\title{
Simulation to Determine The Amount of Fan Rotation on a CoolingMachine Using The Fuzzy Logic Method
}

\author{
Afrizal Hasan Nasution \\ STMIK Budidarma, Indonesia \\ Email : Afrizalnst@gmail.com
}

Received : 06 April 2020

Revised : 18 Mei 2020

Accepted : 01 Juny 2020

(C) 2020 The Author: Published by. Cattleya Darmaya Fortuna

\begin{abstract}
This Fan Rotation Simulation Application on Cooling Machines with Fuzzy Logic is an application that can simulate the fan rotation process based on the input voltage and temperature given by the user. In carrying out this simulation, this application uses a stress index with a category of small, medium, medium, high or higher. Temperature index with categories cooler, cooler, warmer, warmer and hotter. While the fan speed index uses the very slow, slow, rather fast, fast and very fastcategories. This system can analyze the amount of fan rotation in RPM (Rotation Per Minute) automatically based on the input voltage and temperature and is equipped with a graphic facility thatdisplays the simulation results of fan rotation, namely temperature graphs and fan rotation graphs. However. The designed system is equipped with fan rotation speed animation, to simulate fan rotation in the temperature range of $-50 \mathrm{C}$.
\end{abstract}

\section{Keywords: Simulation, Fuzzy Logic, Fan Round}

\section{INTRODUCTION}

Today's society has a high interest in the use of air conditioners (AC) [1]. Determining the optimal temperature in the room is very important because the optimal temperature will have a positive effect on health and energy savings [2]. Indoor air conditioners are used toregulate humidity, heating and cooling of the air in the room. This conditioning aims to provide comfort, so as to reduce fatigue. To get the air temperature in accordance with the desired lot, alternatives can be applied, among others, by increasing the condensation heattransfer coefficient and by increasing the speed of cooling air in the condenser, a larger coefficient of performance will be obtained [3]. Ptemperature and humidity checks are necessary to prevent harmful chemical reactions [4]. In using an ordinary air conditioner, using a remote control to determine the desired room temperature value and the machine will automatically speed up or slow down the fan rotation for the desired temperature choice. Remote control can connect with robot if the obstacle is less than 7 walls [5]. As for the type of air conditioner that has fuzzy logic, the machine always checks the room temperature and adjusts the room temperature itself. For example, if the room temperature becomes cold, the engine will reduce the fan rotation and vice versa, if the room temperature gets colder, the fan rotation will accelerate. This means that the cooling machine that uses fuzzy logic can function automatically in setting the fan speed to adjustthe temperature itself to the surrounding environment. With technology like this it will be more efficient in the use of electrical power. In real situations, to automate the fan rotation process on the cooling machine, several sensors are used to detect such as photo resistive 
sensors to detect the temperature in a room [6] and sensors to detect temperature [7]. Temperature is one of the things that greatly affects the performance of the device [8]. Unfortunately, it is not easy to mathematically relate the room temperature to the desired number of people. Therefore, to formulate the relationship between the two, fuzzy logic technology can be used. By determining membership and fuzzy logic rules in the microcontroller as the brain, the temperature can be adjusted automatically [9]. Therefore, this study aims to evaluate engine speed (rpm) against changes in temperature [10]. The rotation per minute (RPM) fluctuation correction method, was developed to consider the effect of frequency modulation through the correction of the predicted signal [11].

\section{METHODS}

\section{Fuzzy Logic}

Fuzzy logic is one of the sciences that can analyze uncertainty[12]. Fuzzy Logic Control is a system control method based on knowledge base, using fuzzy logic as a method of decision making. This method can adjust the system output based on changes in input parameters due to changes in ambient conditions[13].In designing a control system using fuzzy logic, there are three processes, namely fuzzification, rule evaluation and defuzzification. Each of these processes will affect the response of the controlled system. Defuzzification is the last step in a fuzzy logic system with the aim of converting each result from the inference engine which is expressed in the form of a fuzzy set to a real number. The result of the conversion is the action taken by the fuzzy logic control system. Therefore, the selection of the appropriate defuzzification method also affects the fuzzy logic control system in producing the optimum response[14].

\section{Fan Spin}

In a cooling machine or blower, the fan rotation determines the amount of air that will be exhaled or vice versa. The direction of rotation of the fan determines the air circulation. Clockwise rotation, the fan will draw air from below and circulated upwards and directed downwards again. The reverse rotation (clockwise), then the fan will draw air from the topand exhaled to the bottom. Therefore we need a system that can control the fan rotation speed automatically by adjusting the sitting position of people and the air temperature in the room so that it can save the use of electrical energy, time and energy.[15]. The tools used in this research are:

1. Minimum Pentium 3 microprocessor

2. HDD

3. RAM minimum $64 \mathrm{MB}$

4. Super VGA monitor

5. Keyboard

6. Mouse

7. Flashdisk

8. Windows XP9.

9. VB 6.0

\section{RESULTS \& DISCUSSION}

\section{Simulation Stage}

Fuzzy logic application is implemented using Microsoft Visual Basic 6.0 programming language in interface design and system interaction settings. The system designed is a simulation to determine the fan rotation in the Air Conditioner using the fuzzy method. The determination of the fan rotation is based on input in the form of temperature and voltage. The input is then processed to produce an output in the form of a large fan rotation for the cooling process with several defuzzification methods. 
https://doi.org/10.54209/jurnalkomputer.v12i01.14

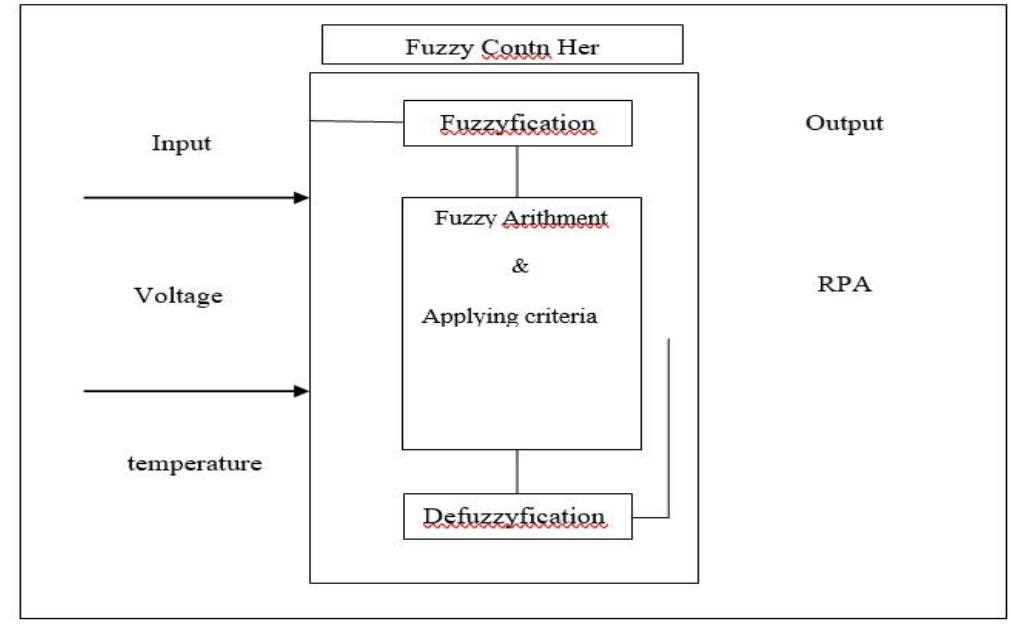

Figure 1: Diagram of how the program works

Step 1: Input

a. Select "Simulation Form".

b. Input the mains voltage on the voltage form

c. Input the temperature on the temperature formStep

2: Process

a. Select "Simulation Start Button".

b. Click the Simulation Start ButtonStep

3: Output

a. Voltage Condition Result

b. Result Temperature Condition

c. Fan Spin ResultsStep

4: Done

\section{Testing Data With VB}

The results of the implementation of the designed software are as follows:

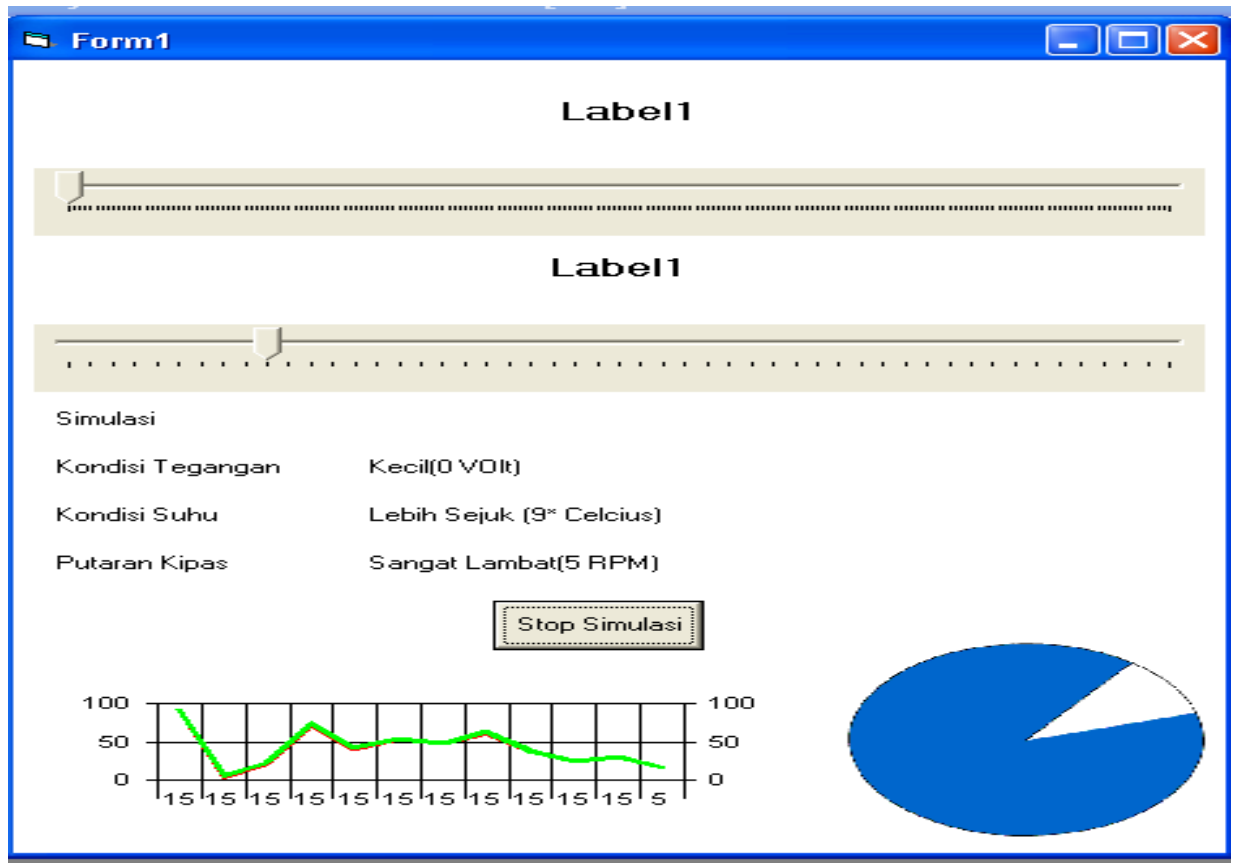


https://doi.org/10.54209/jurnalkomputer.v12i01.14

Figure 2: Simulation Form Display

Simulation Form is the form that is displayed first when the software is running. Simulation form contains voltage slider, dap temperature slider. Simulation button to start the simulation process. The RPM Temperature Graph is a graph that shows the simulation results based on the number of simulations performed.

\section{System Testing Techniques}

The system test uses a time scale, where 1 second represents 1 minutes. The writing carried out 10 simulation tests of fan rotation on the software, the results of which can be seen in Table 1.

Table 1: Fan Simulation Test Results, Wind

\begin{tabular}{|c|c|c|c|c|c|}
\hline No & Voltage) & $\begin{array}{l}\text { Temperature } \\
\text { (Celsius) }\end{array}$ & $\begin{array}{c}\text { Fan Speed } \\
\text { (RPM) }\end{array}$ & $\begin{array}{l}\text { Temperature } \\
\text { Condition } \\
\text { (Celsius) }\end{array}$ & $\begin{array}{c}\text { Fan Speed } \\
\text { Condition } \\
\text { (RPM) }\end{array}$ \\
\hline 1 & 110 & 10 & 5 & $\mathrm{LS}$ & $\overline{S L}$ \\
\hline 2 & 110 & 15 & 5 & LS & SL \\
\hline 3 & 110 & 20 & 5 & $\mathrm{~S}$ & SL \\
\hline 4 & 110 & 25 & 15 & $\mathrm{H}$ & air conditioning \\
\hline 5 & 110 & 30 & 15 & $\mathrm{H}$ & air conditioning \\
\hline 6 & 220 & 10 & 6 & LS & $\mathrm{L}$ \\
\hline 7 & 220 & 15 & 6 & $\mathrm{~S}$ & $\mathrm{~L}$ \\
\hline 8 & 220 & 20 & 6 & $\mathrm{H}$ & $\mathrm{L}$ \\
\hline 9 & 220 & 25 & 15 & $\mathrm{H}$ & $\begin{array}{c}\text { air } \\
\text { conditioning }\end{array}$ \\
\hline 10 & 220 & 30 & 15 & $\mathrm{H}$ & $\mathrm{C}$ \\
\hline
\end{tabular}

Information:

Temperature
a. LS: It's cooler
b. S : Cool
c. $\mathrm{H}:$ Warm

Spin: Fan Cycle
a. SL : Very Slow
b. AC: A bit fast
c. L : Slow

1. If the input voltage is 110 Volts and the input temperature is $10^{\circ} \mathrm{C}$, then the simulation results of the fan rotation speed obtained are S RPM

2. If the input voltage is 110 Volts and the temperature is increased by $150 \mathrm{C}$, then the simulation results for the fan rotation speed obtained are 5 RPM.

3. If the input voltage is 110 Volts and the input temperature is $20^{\circ} \mathrm{C}$, then the simulation results for the fan rotation speed obtained are S RPM.

4. If the input voltage is 110 Volts and the input temperature is $25^{\circ} \mathrm{C}$, then the simulation results for the fan rotation speed obtained are 15 RPM.

5. If the input voltage is 110 Volts and the input temperature is $30^{\circ} \mathrm{C}$, then the simulation results for the fan rotation speed obtained are 15 RPM.

6. If the input voltage is 2120 Volts and the input temperature is $10^{\circ} \mathrm{C}$, then the simulation results for the fan rotation speed obtained are 6 RPM.

7. If the input voltage is 220 Volts and the input temperature is $150 \mathrm{C}$, then the simulation results for the fan rotation speed obtained are 6 RPM.

8. If the input voltage is 220 Volts and the input temperature is $20^{\circ} \mathrm{C}$, then the simulation 
results for the fan rotation speed obtained are 6 RPM.

9. If the input voltage is 220 Volts and the input temperature is $2: \mathrm{i}^{\circ} \mathrm{C}$, then the simulation results for the fan rotation speed obtained are 15 RPM.

10. If the input voltage is 220 Volts and the input temperature is $30^{\circ} \mathrm{C}$, then the simulation results for the fan rotation speed obtained are 15 RPM.

The test results for all of the above criteria have worked well, even the test program has produced the expected temperature by using fuzzy logic.

\section{Strengths and Disadvantages of the Designed System}

The advantages of this system are:

1. This system can analyze the amount of fan rotation in RPM (Rotation Per-Minute) units automatically based on the input voltage and temperature.

2. The designed system is equipped with graphic facilities that display the simulationresults of fan rotation, namely temperature graphs (Celsius) and fan rotation (RPM).

3. This system can also input the temperature automatically.

While the drawback of this system is that the system can only be used to simulate fan rotation in the temperature range of $5^{\circ} \mathrm{C}$ to $50^{\circ} \mathrm{C}$.

\section{CONCLUSION}

Based on the discussion that has been done regarding the fan rotation speed simulation for the input voltage and temperature using fuzzy logic, the following conclusions can be drawn: This software can be used to simulate the fan rotation speed so that the most effective voltage and temperature can be known to get the appropriate fan rotation speed. The software is equipped with a graphical facility for displaying simulation results, namely temperature graphs (Celsius) and fan rotation (RPM). The designed system is equipped with fan rotation speed animation, to simulate fan rotation in the temperature range of $-50 \mathrm{C}$.

\section{REFERENCES}

[1] IS Jati and M. Rivai, "Implementation of Thermal Cameras in Air Conditioning Settings," $J$. Tech. ITS, vol. 8, no. 2, 2019.

[2] I. Aswad, "Introduction to the Fuzzy Tsukamoto Method," Ethos (Journal of Research and Community Service), vol. 4, 2015.

[3] S. Siagian, "ANALYSIS OF CONDENSOR PERFORMANCE CHARACTERISTICS IN A COOLING SYSTEM (AIR CONDITIONING) USING FREON R-134a BASED ON VARIATIONS OF COOLING FAN ROUND," Tech Building., vol. 11, no. 2, 2017.

[4] AY Rangan, Amelia Yusnita, and Muhammad Awaludin, "Monitoring System based on Internet of things on Air Temperature and Humidity at XYZ Chemical Laboratory," J. EKomtek, vol. 4, no. 2, 2020.

[5] LMF Aulia, S. Adi Wibowo, and N. Vendyansyah, "APPLICATION OF IoT IN THE DESIGN OF FIRE EXTINGUISHING MINIATURE SYSTEMS TO ASSIST THE PRE EVACUATION PROCESS," JATI (Jurnal Mhs. Tek. Inform., vol. 5, no.1, 2021.

[6] NI Khoiron, D. Titisari, and L. Lamidi, "Waterbath Design Equipped with Temperature Distribution Monitoring," J. Teknokes, vol. 12, no. 2, 2019.

[7] Y. Ardiyanto and MY Mustar, "DESIGNING GRAPHICAL USER INTERFACE AS A WIRELESS MONITORING SYSTEM DETECTION OF RAIN, TEMPERATURE AND HUMIDITY," J. Electrical Education, vol. 4, no. 1, 2020.

[8] J. Arifin, H. P, and B. Gultom, "Arduino Uno-Based Server Room Temperature Detection and Fan Drive Using SMS Report," Electrician, vol. 12, no. 2, 2019. 
[9] AR Putri, PN Rahayu, and YY Ginantaka, "ROOM TEMPERATURE CONTROL BASED ON ARDUINO 2560," JIPI (Journal of Science. Researchers and Learning Inform., vol. 6, no. $1,2021$.

[10] A. Prasetyo and A. Surono, "Experimental Study of Radiator Temperature Movement Against Engine Speed (RPM) with Constant Fan Speed," Create. res. eng., vol. 1, no. 1, 2021.

[11] D. Han, DY Gwak, and S. Lee, "Noise prediction of multi-rotor UAV by RPM fluctuation correction method," J. Mech. science. Technol., vol. 34, no. 4, 2020.

[12] CPP Maibang and AM Husein, "Predicting the Amount of Palm Oil Production Using the Mamdani Fuzzy Inference System," J. Teknol. and Computer Science. Prime, vol. 2, no. 2, 2019.

[13] Cahyadi, S. Suprijadi, and A. Siswanto, "Control of Fan Motor Rotation Speed for Beverage Cooling Using Fuzzy Logic Control Method Based Microcontroller Atmega 328," J. Ciastech, no. September, 2018.

[14] S. Sutikno and I. Waspada, "COMPARATIVE DEFUZZIFICATION METHOD OF FUZZY LOGIC CONTROL SYSTEM MAMDANI MODEL ON DC MOTOR," J. Masy. information., vol. 2, no. 3, 2012.

[15] F. Nugroho, M. Saleh, and A. Elbani, "Design of an Automatic Fan Control SystemBased on NodeMCU v3," J. Tech. Electrical Univ. Tanjungpura, vol. 2, no. 1, 2020. 